\title{
Mammography screening: an incremental cost effectiveness analysis of two view versus one view procedures in London
}

\author{
Stirling Bryan, Jacqueline Brown, Ruth Warren
}

\begin{abstract}
Study objective - To compare the costs and effects of routine mammography screening by a single mediolateral-oblique view and two views (mediolateral-oblique plus craniocaudal) of each breast.

Design - A cost effectiveness analysis of a prospective non-randomised trial comparing one and two view mammography screening was carried out at St Margaret's Hospital, Epping. All women in the study had two view mammography. The mediolateral-oblique view was always the first image read by the radiologist. After reading the films for a clinic session, the same radiologist then went back and read both the mediolateral-oblique and craniocaudal views together. Each set of films was read by two radiologists. The main outcome measures were recall rates, number of cancers detected, screening and assessment costs, and cost effectiveness ratios.

Subjects - A total of 26430 women who attended for breast screening using both one and two view mammography participated. A sample of 132 women attending for assessment provided data on the private costs incurred in attending for assessment.
\end{abstract}

Results - There was a reduction in the recall rate from $9 \cdot 1 \%$ (2404 of 26430 ) after one view screening to $6 \cdot 7 \%$ (1760 of 26430 ) after two view screening. The results also suggest that for every 10000 women screened an additional five cancers would be detected earlier with two view screening. The additional health service screening cost associated with two view screening was estimated to be $£ 3 \cdot 63$ : the costs associated with one and two view screening policies were estimated to be $£ 41.49$ and $£ 32.99$ respectively. Private costs incurred were estimated to be $£ 0.35$ per woman screened and $£ 32.75$ per woman assessed. Two cost effectiveness ratios were calculated: an incremental health service cost per additional cancer detected of $£ 4129$ and an incremental health service plus private cost per additional cancer detected of $£ 2742$. The sensitivity analysis suggested that the results were sensitive to relatively large changes in a number of parameters. These included screening costs, assessment costs, equipment life, and recall rates.

Conclusions - Use of two view screening increased early cancer detection and also costs. The reduction in the recall rate with two views was not sufficiently large to make the cost of two view screening neutral. While these results are not completely generalisable, a framework is provided to allow other centres to estimate the cost effectiveness of two view screening in their locality.

\section{( $(\mathcal{E}$ Epidemiol Community Health 1995;49:70-78)}

Most mammography screening in the UK tends to be undertaken using a single, mediolateraloblique view of each breast. ${ }^{1}$ This policy was recommended in the Forrest report ${ }^{2}$ in the absence of convincing evidence on the costs and benefits of two view (mediolateral-oblique plus craniocaudal) screening. A recent review of this by van Dijk et $a l,{ }^{3}$ however, indicated that there is still uncertainty about the relative effectiveness of two view screening and argued for a prospective evaluation in an actual screening situation. Two view screening may be more effective in terms of detecting more early tumours and recalling fewer women without tumours for further assessment. The second view may provide additional information to help determine whether an abnormality seen on the first view warrants further investigation or to detect abnormalities not seen on the first view. It almost certainly involves additional screening costs in that at least two extra films per woman are used and extra time is involved in taking and interpreting the second film. A lower recall rate may have implications in terms of the costs and the degree of anxiety in screened women, however, since the number recalled unnecessarily for assessment may also be lower.

Two view screening, thus, has the potential to be more effective than one view screening in detecting tumours, while screening costs are likely to be higher and the costs of assessment may be lower. This paper reports the first relative cost effectiveness analysis of two view versus one view mammography screening and is based on data collected prospectively in a prevalence screening round at St Margaret's Hospital, Epping. The emphasis of the paper is on the analysis of the additional costs incurred in operating a two view screening policy. A cost effectiveness analysis is also presented in which the additional costs of two view screening are compared to the additional benefits in terms of additional cancers detected. 


\section{Methods}

EFFECTIVENESS

Data on the relative effectiveness of two view compared with one view breast screening were collected as part of a prevalence round of a population screening programme between 1988 and 1991, where women between the ages of 50 and 64 were routinely invited for screening. Screening was largely undertaken in two mobile vehicles, but $20 \%$ of women were screened at St Margaret's. All women were invited to have two films taken. They were advised that the government's guidelines recommended only one view and were informed that the second view was part of a research project to investigate the benefit of the second view. A proportion (22\%) of women chose to have only one view.

The mediolateral-oblique view was always the first image read by the consultant radiologist and the report was expressed as a "Yes" or "No" for patient recall. After reading the films for one clinic session, the same radiologist then went back and read both the mediolateraloblique and craniocaudal views together and the findings were reported in a similar manner. Each set of films was read by two radiologists. These data provide information on the difference in recall rates between one and two view screening. For all women found to have cancer at assessment, the recall recommendation with one view was compared to that with two views in order to establish the difference in the cancer detection rate between the two forms of screening. A woman was assumed to be recalled if at least one of the radiologists recommended recall. Since we have only one patient sample in this study, differences between one and two view screening in terms of recall rates and cancer detection rates were tested using McNemar's test. ${ }^{4}$ Further details of the clinical evaluation are available from RW.

\section{RESOURCE USE AND COSTS}

The objective of the cost analysis was to identify and estimate all additional resources associated with the taking of a craniocaudal view in addition to the standard mediolateral-oblique view in routine breast screening. A broad perspective was adopted in the cost analysis with both health service and women's and their companions' own resource use being considered. The additional costs associated with the process involved in taking and reading the additional images were identified. Similarly, the costs associated with the assessment of women after a positive result on screening by single view mammography were also identified to give an indication of the potential savings that might be achieved if two view screening has the effect of reducing the recall rate. In addition, the difference in costs associated with an assessment clinic attendance after two view mammography compared with the costs after one view mammography was identified. All costs have been brought to an April 1993 price base.

Screening costs

The additional health service radiographic and reporting costs associated with two view screening were estimated by considering the labour, consumable items, overheads, and capital items involved. The additional radiographic labour and consumable requirements associated with taking the second view were based on the judgement of senior radiographic staff at St Margaret's. The average time taken by the consultant radiologist to read and report on an image was measured by observing the reporting of 210 images in 60 minutes. These data were combined with the employment cost per minute, net of annual leave entitlement, for the relevant personnel which were estimated from the West Essex Health Authority Breast Screening Programme budget statement for 1992-93. The costs of additional films were based on the actual price paid by St Margaret's. The cost of films repeated for technical reasons were excluded from the analysis. Energy costs, taken from the hospital budget statement, were allocated on the basis of space occupied and divided by the number of minutes in each working day to give an energy cost per minute occupying a room. There is no reason to believe that the other overhead costs associated with screening would differ between one and two view screening.

The costs of additional capital items required for two view screening were based on current valuations of replacement costs amortised at a discount rate of $6 \%$ over the expected useful life of the equipment. Capital items used in both two and one view screening were identified and the reduced life expectancy of the equipment as a result of its more intensive use under two view screening was based on the judgements of the radiologist at St Margaret's and representatives of the manufacturers. An average additional equipment capital cost per woman screened was calculated by dividing the total additional capital cost per annum incurred in screening by the number of women attending for breast screening in the year 1992. The additional buildings capital cost associated with the additional time spent occupying the hospital rooms or screening units during the screening process was based on the health service capital charges levied. A capital charge per minute for the hospital rooms of interest and the screening units was calculated by dividing the costs by the number of working minutes in a year.

The additional woman's time used in two view screening was also based on the judgement of senior radiographic staff. An estimate was made of the proportion of women who gave up work time. This was based on the data collected on a sample of women attending for assessment at St Margaret's during 1992, described later. Working time was valued using average local pay rates, increased for employer's $\operatorname{costs}^{5}$ and, in line with guidelines generated for use in transport appraisals, ${ }^{67}$ a constant value per minute was used to value non-working time.

Health service costs of assessment

The resource use associated with assessment procedures after one view mammography 
screening were based on clinical judgement and data collected on women attending assessment at St Margaret's between 1 September 1988 and 31 August 1989. The average unit cost of the assessment procedures was estimated by considering the labour, consumable items, overheads, and capital items involved.

Labour time and consumable items were identified by observation and consultation with the radiographic staff at St Margaret's. With the exception of the costs associated with reading fine needle aspiration (FNA) cytology, data were taken from the 1992-93 budget statement and supplier list prices (inclusive of value added tax) to estimate the labour and consumable costs, using the methods described above under screening. The laboratory cost of an FNA cytology reading was included under consumable items but actually included some labour, overhead, and capital costs which were taken from the cytology laboratory estimates provided to the Audit Commission. The cost of films repeated for technical reasons were not included in the analysis.

Overheads were estimated using data from the 1992-93 budget statement. Routine statistics on the numbers screened and assessed for the year 1992-93 and data collected on the proportion of women requiring follow up assessment visits were used to estimate the total number of screening and assessment attendances. The annual budget allocated to overheads, with the exception of fuel, was then divided by the estimated number of screening and assessment attendances in any one year to give the relevant costs per attendance. The same fuel estimate per minute were used as for screening.

Equipment maintenance costs, taken from the 1992-93 budget, were split evenly between the three mammography machines, the ultrasound equipment, and the roller viewer. One mammography machine was available for assessment $20 \%$ of the time. The other two machines and the roller viewer were used for screening only. Thus, $20 \%$ of the maintenance cost of one mammography machine was divided by the estimated number of assessment visits during 1992-93 to give a maintenance cost per visit. The ultrasound equipment was used $50 \%$ of the time by the assessment clinic. Thus, $50 \%$ of the maintenance cost of the ultrasound equipment was divided by the estimated number of women having ultrasound at assessment during 1992-93 to give the maintenance cost per woman examined by ultrasound.

The capital equipment associated with each of the assessment procedures was identified. On the basis of judgements by representatives of the manufacturers and the radiologists at $\mathrm{St}$ Margaret's, the capital equipment was taken to have a life expectancy of eight years, with the exception of the processor which was taken to have a life of seven years. Twenty per cent of the annual capital cost of the mammography unit and $6.8 \%$ of the two processors were apportioned to assessment, on the basis of information provided by the consultant radiologist. A discount rate of $6 \%$ was then used to estimate the annuity cost of the capital. Capital costs were then divided by the number of women assessed in any one year to give the capital cost per women assessed.

In the case of the ultrasound equipment, $50 \%$ of the annual capital cost was attributed to assessment and divided by the estimated number of women having ultrasound in any one year. Similarly, the capital cost of the perforated plate used for FNA cytology was solely attributed to the assessment clinic and divided by the number of women having FNA at their first assessment visit in any one year. The capital cost of an $x$ ray tube was assumed to be the same as that for screening, as was the building cost.

The estimate of resource use in assessment procedures after two view mammography was also based on clinical judgement. The costs associated with women still requiring assessment after two view mammography were estimated using similar methods to those described above. However, the costs of mammography were adjusted for the fact that women would no longer require a craniocaudal view at their first assessment visit and fewer women would require magnification views.

\section{Private costs of assessment}

The costs incurred by women and their companions in attending the hospital for an assessment clinic were obtained through the use of a questionnaire distributed to a sample of 150 consecutive attenders at St Margaret's. The questionnaire was distributed at the end of the woman's assessment visit. This sample of women was not part of the study population used to collect the data on effectiveness. The questionnaire is very similar to that used in another study which identified the costs women incur in attending for breast screening. ${ }^{8}$ Data were collected on women's and companions' travel arrangements to and from the hospital in order to estimate their travel costs: the distance travelled, the mode of travel and, where appropriate, the out of pocket costs of the journey. Where private cars were used, women were requested to estimate total mileage. An appropriate average cost per mile was then used to estimate the cost of the journey, which allows for fixed costs, depreciation, and running costs. ${ }^{9}$ If the woman was accompanied, and the companion had no appointment at the hospital, then the companion's transport cost was also included in the travel cost.

The questionnaire also elicited information on the time spent travelling to the hospital, the time involved in the clinic, and the activities forgone by the woman and her companion. The data on activities forgone were used to value travel and attendance time. An assumption was made that all companions were men and that they all gave up work time. Women's and companions' forgone working times were valued using average local hourly pay rates, increased to account for employers' costs, and this method was used regardless of whether the woman or the employer actually incurred the cost. ${ }^{5}$ Non-working time was given 
Table 1 The additional health service costs $(f)$ per woman screened of two view versus one view mammography

\begin{tabular}{llllll}
\hline & Labour & Consumables & Overheads & Capital & Total \\
\hline Additional radiographic costs & 0.76 & 0.75 & 0.04 & 1.56 & 3.11 \\
Additional reporting costs & 0.37 & - & 0.02 & 0.13 & 0.52 \\
\hline
\end{tabular}

a constant value, again using guidelines generated for use in transport appraisals. ${ }^{67}$

\section{COST EFFECTIVENESS ANALYSIS}

To compare the additional costs and benefits of two view screening with other potential uses of health services resources, cost effectiveness ratios have been developed. The additional health service cost of two view screening was calculated as part of the cost analysis and the additional number of cancers detected with two views was estimated in the assessment of effectiveness. The ratios were expressed as the incremental health service cost per additional cancer detected and the incremental health service plus private cost per cancer detected. The total additional cost was calculated using the formula below.

Total additional cost $=$

$$
\mathrm{N} \times(\mathrm{a}-((\mathrm{r} 1 \times \mathrm{b})-(\mathrm{r} 2 \times \mathrm{c}))) \text { : }
$$

Where $\mathbf{N}=$ Number of women screened

a $=$ Additional screening cost

$\mathrm{b}=$ Cost of assessment following one view screening

c $=$ Cost of assessment following two view screening

$\mathrm{r} 1=$ One view recall rate

$\mathrm{r} 2=$ Two view recall rate

The cost effectiveness ratios allow comparison with other cancer screening interventions which have been evaluated and have expressed their results in a similar manner, such as that for colorectal cancer by Whynes et al. ${ }^{10}$ The intervention with the lowest cost per unit gain in effectiveness is seen as being the more efficient and, potentially, a better use of resources.

\section{SENSITIVITY ANALYSIS}

A number of assumptions have been made in the analysis with regard to some of the key resource use and effectiveness parameters. As a result there is some uncertainty surrounding our cost and effectiveness estimates and, thus, our results may not be generalisable to all screening centres. None the less, a framework is provided on the basis of our analysis that allows other centres, which may have different values for specific parameters, to estimate whether introduction of two view screening would be cost effective for them. The sensitivity analysis gives an indication of the parameters for which the results of our analysis are most sensitive to change.

The parameters varied in the analysis are listed in table 6 with the base case value for the parameter and the extent of the variation. Recall rates were varied within the range identified by Chamberlain $e t$ al ${ }^{11}$ for the UK breast screening programme. The health service and private screening and assessment costs were all separately reduced by an arbitrary $20 \%$. Further scenarios were also considered where the proportion of women receiving clinical examination, ultrasound, and FNA at assessment were reduced separately by $20 \%$; where the equipment life and the proportion of women having follow up were unchanged by two view screening; and where the discount rate was $4 \%$.

\section{Results}

\section{EFFECTIVENESS}

The clinical findings relevant to the economic evaluation are the reduction in the recall rate and the additional number of cancers detected as a result of two view mammography screening. Using data on the 26430 women who had two view mammography, the clinical findings suggest a reduction in the recall rate from $9 \cdot 1 \%$ (2404 of 26430 ) to $6 \cdot 7 \%$ (1760 of 26430 ). This difference can be attributed to two view screening during the study period 1988-91 $(p<0.001)$. In the 26430 women screened, 205 cancers would have been detected as a result of screening if a one view policy had been operating and 219 would have been detected had a two view policy been operating. Therefore, the cancer detection rates were $7 \cdot 8$ per 1000 women screened with one view screening and 8.3 per 1000 women screened with two view screening $(p<0 \cdot 01)$. Thus, for every 2000 women screened, the second view allowed the early detection of one additional cancer.

Table 2 The health service costs $(£)$ per assessment procedure

\begin{tabular}{|c|c|c|c|c|c|c|}
\hline Procedure & & Labour & Consumables & Overheads & Capital & Total \\
\hline \multirow[t]{3}{*}{ First assessment visit } & $\begin{array}{l}\text { One craniocaudal view of each } \\
\text { breast } \\
\text { One craniocaudal view of each }\end{array}$ & 5.68 & $0 \cdot 68$ & $1 \cdot 47$ & $3 \cdot 88$ & $11 \cdot 71$ \\
\hline & $\begin{array}{l}\text { views of breast with abnormality } \\
\text { Two magnification views of breast }\end{array}$ & $7 \cdot 80$ & 1.36 & 1.51 & $4 \cdot 79$ & $15 \cdot 46$ \\
\hline & $\begin{array}{l}\text { with abnormality } \\
\text { Clinical examination } \\
\text { Ultrasound examination } \\
\text { Fine needle aspiration cytology }\end{array}$ & $\begin{array}{l}5 \cdot 68 \\
1 \cdot 04 \\
1 \cdot 56 \\
6 \cdot 88\end{array}$ & $\begin{array}{l}0.68 \\
- \\
\overline{25} \cdot 48\end{array}$ & $\begin{array}{l}1 \cdot 47 \\
0 \cdot 02 \\
3 \cdot 22 \\
0 \cdot 12\end{array}$ & $\begin{array}{l}3 \cdot 88 \\
0 \cdot 26 \\
2 \cdot 96 \\
1 \cdot 99\end{array}$ & $\begin{array}{r}11 \cdot 71 \\
1 \cdot 32 \\
7 \cdot 74 \\
34 \cdot 47\end{array}$ \\
\hline Follow up visit ${ }^{*}$ & $\begin{array}{l}\text { One mediolateral-oblique view of } \\
\text { each breast and one craniocaudal } \\
\text { view of breast with abnormality }\end{array}$ & $2 \cdot 56$ & $1 \cdot 02$ & $1 \cdot 49$ & $1 \cdot 85$ & 6.92 \\
\hline
\end{tabular}


Table 3 The expected health service cost $(£)$ per woman attending assessment

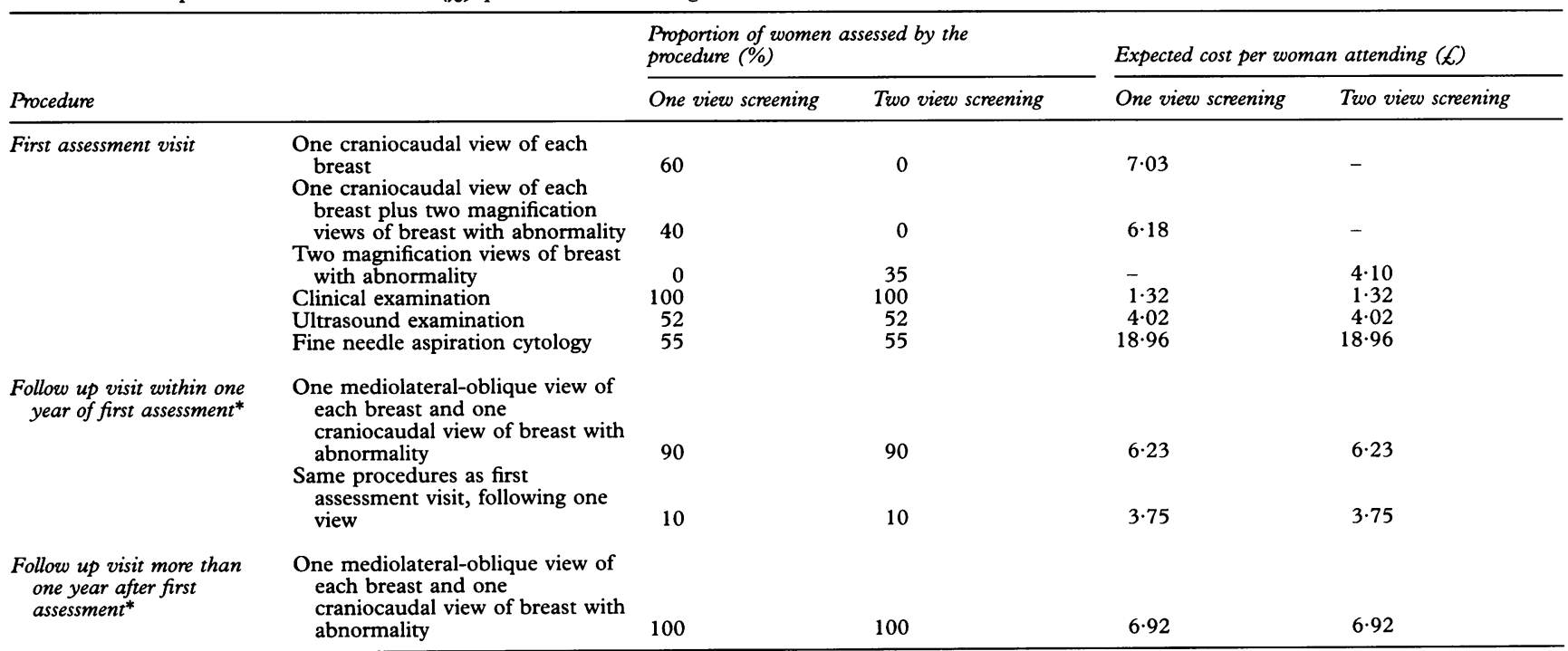

* Costs are undiscounted.

RESOURCE USE AND COSTS

Screening costs

The additional health service radiographic costs associated with operating a two view mammography screening programme and the additional health service reporting costs are shown in table 1 . The total additional health service costs of screening with two view mammography is, therefore, $£ 3.63$ per women screened. On average, $2 \cdot 2$ additional films per woman screened are required and the extra screening and processing time is about four minutes. The only additional capital requirements are four $x$ ray cassettes. The other capital items were judged to have a shortened life expectancy of about $20 \%$ because of their more intensive use. The additional private cost associated with two view screening results from each screened woman being delayed by about three minutes while the second view is taken. The private cost associated with this was estimated to be $£ 0 \cdot 35$.

\section{Health service assessment costs}

The health service costs associated with each assessment procedure are shown in table 2 . These costs have been broken down into labour, consumable items, overheads, and capital. Nine minutes of the radiographer's and nurse counsellor's time, and four minutes of the consultant radiologist's time were thought to be associated with the craniocaudal view of each breast. Where an additional two magnification views of the abnormal breast were taken, the radiographer and nurse counsellor were thought to devote about 13 minutes of their time and the radiologist about five minutes of her time. Where only two magnification views were taken at assessment after two view mammography, the judgement was made that this would take those involved about the same amount of time as two craniocaudal views.

Clinical and ultrasound examinations by the consultant radiologist were thought to take a total of two and three minutes respectively, and FNA a total of 12 minutes of the radiographer's and nurse counsellor's time and four minutes of the consultant radiologist's time. The costs associated with clinical and ultrasound examinations and FNA cytology at a woman's first assessment visit after two view screening were assumed to be the same as for those after one view screening.

The variations in resource use and cost associated with assessment after one view and two view screening are shown in table 3 . At the first assessment visit after one view screening, the judgement was made that $60 \%$ of women would just have a craniocaudal view of each breast. The remaining $40 \%$ have two magnification views of the breast with an abnormality. After two view screening, $35 \%$ of assessed women were expected to have two magnification views at their first assessment visit, but none was expected to have a craniocaudal view. Data collected on women attending assessment after one view screening between 1 September 1988 and 31 August 1989 suggested that $52 \%$ have an ultrasound examination on their first visit and $55 \%$ have FNA cytology. ${ }^{12}$ These proportions were assumed to be the same after two view screening. This information was combined with the unit cost data to give the average cost of each procedure per woman attending first assessment. Thus, the average cost of a first assessment visit after one view screening was estimated to be $£ 37.51$ and that after two view screening was estimated to be $£ 29 \cdot 05$.

Resource use and cost estimates for follow up assessment visits are shown in tables 2 and 3 . A mediolateral-oblique view and a craniocaudal view of the abnormal breast at follow up assessment were judged to take 11 minutes of the radiographer's time, and 54 seconds of the radiologist's time. The capital costs associated with the mammography machine and processor were included in the costs of the first visit. The judgement was made that $90 \%$ of the women attending for a follow up visit within one year of their first assessment would require mammography only. The remainder would be assessed by the same procedures as in a first 
assessment visit after one view screening. All women having a follow up assessment visit more than one year after their first assessment were thought likely to have mammography only.

The resource use data collected on women attending for assessment suggest that $84 \%$ of all second assessment visits occur after one year and all third visits occur two years after the first visit. ${ }^{12}$ Future costs were discounted at $6 \%$ to give unit costs of $£ 7.06$ and $£ 6 \cdot 16$ respectively for a second and third assessment visit after one view screening. The costs associated with follow up assessment visits after two view screening were estimated in a similar way to give unit costs of $£ 6.95$ and $£ 6 \cdot 16$ respectively for second and third assessment visits. Fifty three per cent of women had a second assessment visit before being returned to routine recall and a further $4 \%$ had a third visit. $^{12}$ These proportions were multiplied by the relevant unit costs to estimate expected total costs for assessment after one view screening of $£ 41.49$, and that after two view screening of $£ 32 \cdot 99$.

\section{Private cost of assessment}

Tables 4 and 5 detail the private costs incurred by women and their companions in attending hospital for an assessment clinic. One hundred and thirty two questionnaires were returned, giving a response rate of $88 \%$. The mean (SD) distance travelled to and from hospital was $29 \cdot 23(25 \cdot 29)$ miles and, clearly, the most popular mode of transport was the private car. None of the women who returned the questionnaire walked to the hospital. Seventy nine per cent of women were accompanied by someone else for their hospital visit and none of the companions themselves had an appointment at the hospital. In terms of time lost from usual activities, $51 \%$ of patients and $61 \%$ of their companions would otherwise have been involved in paid occupation. Most patients and their companions who would otherwise have been at work were able to take time off without loss of pay; only $8 \%$ of patients and $7 \%$ of companions lost income as a result of attending hospital.

Table 4 Assessment clinic private costs: travel

\begin{tabular}{lcc}
\hline Travel mode & $\%$ & $\begin{array}{l}\text { Mean cost } \\
(£)\end{array}$ \\
\hline Private car & 91.3 & $8.56^{*}$ \\
Public transport & 7.8 & 2.92 \\
Other (eg taxi) & 0.9 & 30.00 \\
Total expected cost & & \\
per woman & & 10.74 \\
\hline
\end{tabular}

* Based on car with engine capacity between 1001 and $1400 \mathrm{cc}$ with 20000 miles pa.

Table 5 Assessment clinic private costs: time

\begin{tabular}{lll}
\hline & $\begin{array}{l}\text { Mean time } \\
(\text { min })\end{array}$ & $\begin{array}{l}\text { Mean cost* } \\
(£)\end{array}$ \\
\hline Travel & 41 & $12 \cdot 67$ \\
Assessment & 65 & $20 \cdot 08$ \\
Total & & $32 \cdot 75$ \\
\hline
\end{tabular}

* Includes time costs of a companion where the woman was accompanied by someone else to the clinic.
COST EFFECTIVENESS ANALYSIS

The results indicate that for every 10000 women screened, the additional cost of two view screening to the health service alone would be of the order of $£ 20647$. When the private costs of time and travel associated with screening and assessment visits are also included, the additional total cost for every 10000 women screened is only $£ 13710$. The primary unit of effectiveness chosen for the cost effectiveness analysis was the additional number of cancers detected. For every 10000 women screened one would expect an additional five cancers to be detected with a two view screening policy. Two cost effectiveness ratios can, therefore, be calculated: an incremental health service cost per additional cancer detected of $£ 4129$; and an incremental health service plus private cost per additional cancer detected of $£ 2742$.

\section{SENSITIVITY ANALYSIS}

Table 6 shows the main results of the sensitivity analysis. The only cost parameters listed are those that resulted in a greater than $20 \%$ change in one of the cost effectiveness ratios. The results of the cost effectiveness analysis are not highly sensitive to variation in private costs or health service reporting costs. They are, however, most sensitive to change in radiographic costs, where a $20 \%$ increase leads to a $30 \%$ increase in the health service cost per cancer detected, and to changes in assessment costs after one view screening, where a $20 \%$ increase leads to a $37 \%$ reduction in the health service cost per cancer detected. If we assume that assessment clinic costs after one view screening are the same as those after two view screening, the health service cost per cancer detected increases by up to $38 \%$. Moreover, the sensitivity analysis shows that a lower cost of assessment increases the cost per cancer detected as a result of two view mammography.

The cost effectiveness ratios seem to be insensitive to changes in the discount rate: a $4 \%$ rate increases both cost effectiveness ratios by only $1 \%$. They are, however, sensitive to the assumptions regarding the life of capital equipment. For example, the cost effectiveness analysis assumed that equipment life would be shorter with two view screening-by two years for the $x$ ray units and one year for the processors. If, however, it is assumed that equipment life is unaffected, the cost effectiveness ratios are more attractive; reducing the health service cost effectiveness ratio by $32 \%$ and the health service plus private cost effectiveness ratio by $47 \%$.

The cost effectiveness analysis results are not sensitive to changes in the assumptions relating to the proportion of women at assessment who receive a clinical examination, an ultrasound examination, or FNA. Similarly, changes in the assumptions relating to the proportion of women requiring a second and third follow up visit do not have a large impact on the results. In contrast, small changes in the rates of recall after screening do seem to have a large effect on the results. If there was no change in the recall rate with two view screening and it re- 
Table 6 Sensitivity analysis

\begin{tabular}{|c|c|c|c|c|}
\hline Parameter & Base value & $\begin{array}{l}\text { Sensitivity analysis } \\
\text { value }\end{array}$ & $\begin{array}{l}\text { NHS cost per cancer } \\
\text { detected }(\mathcal{f}) \\
(\% \text { change) }\end{array}$ & $\begin{array}{l}\text { NHS }+ \text { private cost } \\
\text { per cancer detected }(£) \\
(\% \text { change) }\end{array}$ \\
\hline Base case & - & - & 4129 & 2742 \\
\hline Radiographic costs & $£ 3 \cdot 11$ & $£ 3 \cdot 73$ & $5373(+30 \%)$ & $3986(+45 \%)$ \\
\hline $\begin{array}{l}\text { Cost of assessment after one view } \\
\text { screening }\end{array}$ & $£ 41 \cdot 49$ & $£ 49 \cdot 79$ & $2619(-37 \%)$ & $1232(-55 \%)$ \\
\hline $\begin{array}{l}\text { Cost of assessment after two view } \\
\text { screening }\end{array}$ & $£ 32.99$ & $£ 39.59$ & $5014(+21 \%)$ & $3626(+32 \%)$ \\
\hline $\begin{array}{l}\text { Cost of assessment after one and two view } \\
\text { screening }\end{array}$ & $\begin{array}{l}£ 41.49(1 \text { view }) \\
£ 32.99(2 \text { view })\end{array}$ & $\begin{array}{l}£ 41.49(1 \text { view }) \\
£ 41.49(2 \text { view })\end{array}$ & $5269(+28 \%)$ & $3881(+42 \%)$ \\
\hline $\begin{array}{l}\text { Cost of assessment after one and two view } \\
\text { screening }\end{array}$ & $\begin{array}{l}£ 41 \cdot 49 \text { (1 view) } \\
£ 32.99 \text { (2 view) }\end{array}$ & $\begin{array}{l}£ 32.99(1 \text { view }) \\
£ 32.99 \text { (2 view) }\end{array}$ & $5677(+38 \%)$ & $4289(+56 \%)$ \\
\hline $\begin{array}{l}\text { Reduction in life of equipment with two } \\
\text { view screening }\end{array}$ & $\begin{array}{l}2 \text { years for } x \text { ray unit } \\
1 \text { year for processor }\end{array}$ & $\begin{array}{l}\text { Zero years for both } x \text { ray } \\
\text { unit and processor }\end{array}$ & $2830(-32 \%)$ & $1442(-47 \%)$ \\
\hline Discount rate & $6 \%$ & $4 \%$ & $4155(+1 \%)$ & $2767(+1 \%)$ \\
\hline $\begin{array}{l}\text { Recall rates after one and two view } \\
\text { screening }\end{array}$ & $\begin{array}{l}0.091 \text { (1 view) } \\
0.067 \text { ( } 2 \text { view) }\end{array}$ & $\begin{array}{l}0.067(1 \text { view }) \\
0.067(2 \text { view })\end{array}$ & $6121(+48 \%)$ & $6821(+148 \%)$ \\
\hline $\begin{array}{l}\text { Recall rates after one and two view } \\
\text { screening }\end{array}$ & $\begin{array}{l}0.091 \text { (1 view) } \\
0.067 \text { (2 view) }\end{array}$ & $\begin{array}{l}0.0464(1 \text { view }) \\
0.0464(2 \text { view })\end{array}$ & $64741(+57 \%)$ & $7171(+162 \%)$ \\
\hline $\begin{array}{l}\text { Recall rates after one and two view } \\
\text { screening }\end{array}$ & $\begin{array}{l}0.091 \text { ( } 1 \text { view }) \\
0.067 \text { ( } 2 \text { view })\end{array}$ & $\begin{array}{l}0.091 \text { (1 view) } \\
0.091(2 \text { view })\end{array}$ & $5713(+38 \%)$ & $6413(+134 \%)$ \\
\hline $\begin{array}{l}\text { Recall rates after one and two view } \\
\text { screening }\end{array}$ & $\begin{array}{l}0.091 \text { ( } 1 \text { view) } \\
0.067 \text { ( } 2 \text { view })\end{array}$ & $\begin{array}{l}0.0685 \text { (1 view) } \\
0.0464(2 \text { view })\end{array}$ & $4637(+12 \%)$ & $3415(+25 \%)$ \\
\hline $\begin{array}{l}\text { Proportion of women attending } \\
\text { assessment who receive clinical } \\
\text { examination }\end{array}$ & $100 \%$ & $80 \%$ & $4137(0 \%)$ & $2750(0 \%)$ \\
\hline $\begin{array}{l}\text { Proportion of women attending } \\
\text { assessment who receive ultrasound }\end{array}$ & $53 \%$ & $42 \%$ & $4163(0 \%)$ & $2776(+1 \%)$ \\
\hline $\begin{array}{l}\text { Proportion of women attending } \\
\text { assessment who receive FNA }\end{array}$ & $55 \%$ & $44 \%$ & $4309(+4 \%)$ & $2922(+7 \%)$ \\
\hline $\begin{array}{l}\text { Proportion of women having follow up } \\
\text { visits }\end{array}$ & $\begin{array}{l}1 \text { follow up visit } \\
(53 \%) \\
2 \text { follow up visits } \\
(4 \%)\end{array}$ & $\begin{array}{l}0 \% \\
0 \%\end{array}$ & $4327(+5 \%)$ & $2940(+7 \%)$ \\
\hline
\end{tabular}

mained at 0.091 then the cost effectiveness ratio (including only health service costs) would be $38 \%$ higher. If the one view recall rate had initially been lower at 0.067 , and again no change in the rate was achieved with two view screening, then the ratio would be $48 \%$ higher. If the one view recall rate was initially lower than the 0.091 found in this study but the reduction in the recall rate was of a similar magnitude to that achieved here then two view screening would be associated with a higher health service cost per cancer detected. Therefore, the sensitivity analysis indicates that the cost parameters for which a precise estimate is important are the health service radiographic costs and the health service assessment costs. The results of the analysis are also highly sensitive to variation in the recall rates following one and two screening and, thus, the accuracy of these parameters is also most important.

\section{Discussion}

The results indicate that in the one centre studied two view screening was significantly more effective than one view screening in terms of early cancer detection but was also more costly. Although these results cannot be generalised in their present form, a framework is provided to allow other screening centres the opportunity to incorporate their own estimates of the important parameters indicated by the sensitivity analysis. In terms of cost parameters, these included the health service costs of the radiographic process and the assessment visit but did not include private costs incurred at screening or assessment. Table 1 shows that labour and consumable and capital items all make an important contribution towards the total additional health service radiographic costs and, thus, accurate estimation of the cost of these items is required. As the results are also sensitive to the cost of assessment visits, other centres should confirm that the nature of assessments at St Margaret's Hospital, outlined in table 2, is similar to that experienced in their centre. If assessments at other centres are very different to those at St Margaret's and this causes the cost of assessment to be very different then the results of the analysis may not be applicable to those centres.

Variation in recall rates also seems to have a large impact on the results: two view screening is an attractive option where a high recall rate on one view is experienced but is less attractive if a low recall rate on one view is already being achieved. The reductions in the life of the capital equipment with two view screening used in the base case analysis were those estimated by the radiographic staff at St Margaret's. The representatives of the equipment manufacturers indicated that they did not expect the equipment life to be any shorter with two view screening. If the manufacturers are correct then the cost effectiveness ratios are very much lower and, thus, a two view policy seems to be a 
more attractive option. However, it is probably unrealistic to assume that no reduction in equipment life will be experienced and we believe that the modest reductions used in our base case analysis are realistic.

Once the cost effectiveness ratios have been determined, the appropriate question is whether the required additional health service resources should be directed towards the adoption of two view mammography screening. In the case of St Margaret's, the question is whether it is worth spending an additional $£ 4000$ of health service money to bring forward the detection of one additional cancer? If we compare our results with those reported in a recent analysis of the cost effectiveness of colorectal cancer screening, ${ }^{10}$ two view mammography screening does not seem to be that attractive an option. The cost effectiveness ratios for colorectal screening ranged from $£ 2236$ to $£ 3449$ (health service cost only at 1989-90 prices) per cancer detected, depending on the method of screening, and such a screening programme is not currently viewed by policy makers as an intervention worthy of funding. When a broader perspective on costs is adopted, and costs incurred by patients are included in the analysis, then a more attractive cost effectiveness ratio for two view screening results. This is due to the fact that two view screening reduces the rate at which women are recalled for assessment and, thus, eliminates the need for some women to make additional visits to hospital. We would urge policy makers to adopt a broad societal perspective and consider private resource use if one of their aims is to promote a more efficient allocation of society's resources.

This analysis has assumed that early cancer detection is itself a good thing and we have not attempted to estimate a link between cancer detection and life years gained or quality adjusted life years gained. It is important, however, to be aware that early cancer detection will, in some cases, merely bring forward the time of the diagnosis without improving the prognosis. A long term mortality follow up study would be required for the effect of two view screening on prognosis to be properly studied. The other "benefit issues" that might be included in such a study are the effect of the increased radiation doses that the population of screened women would receive with two view screening and the avoided anxiety associated with a reduced number of women being recalled for assessment after screening. Our analysis has assumed that the risk of radiation induced cancer associated with the second view is zero. While this is not strictly correct, there is evidence to suggest that the risk is negligible. ${ }^{213}$

Inviting a woman to attend hospital for further investigations after mammography screening almost certainly causes anxiety. Several studies have investigated this issue and all indicate that levels of distress are increased by recall. ${ }^{14-18}$ Most indicate that the raised anxiety is a temporary phenomenon, lasting no longer than three months. A study by Lerman et al ${ }^{15}$ found that beyond three months women with positive mammography results had concerns regarding breast cancer which were causing them both emotional and physical problems. Gram et $a l^{16}$ found that $5 \%$ of women who had a false positive mammography result considered it to be "the worst thing they had ever experienced". However, most women considered the stress invoked by recall to be minor when compared to other common experiences. It is, nevertheless, important to limit the amount of unnecessary anxiety experienced by women who participate in mammography screening and one of the principal ways of achieving this is to reduce the numbers recalled. Two view screening seems to ensure a lower recall rate. Thus, the lower anxiety levels in women, who would otherwise be recalled, should be taken into account when considering the value of adopting a two view screening protocol.

It should be emphasised that this analysis is based on data generated from a prevalence and not an incidence round of mammography screening. In an incidence round one would expect the recall rate after screening to be lower and the number of additional cancers detected to be smaller. Thus, the cost effectiveness ratios quoted in the results are almost certainly underestimates of the ratios that would reflect the situation of two view mammography screening in an incidence round. Two view screening is, therefore, likely to be less cost effective in subsequent incidence rounds. The analysis is also based on data from one screening centre and while the results might be specific to the work patterns of the one centre studied, we have given a very detailed account of how the cost analysis was undertaken and so it should be possible for other centres to estimate how the results would differ for their situation. Much of the uncertainty regarding effectiveness and costs of two view screening would be removed if data were available from a randomised controlled trial in which half of the screened women received two view mammography and half received one view.

The authors would like to thank Martin Buxton, Mark Sculpher and Andrew Briggs for their helpful comments on an early draft Thanks also to Jo Holland and Emma Farrant for secretaria support. Stirling Bryan and Jacqueline Brown are funded by the Department of Health.

1 Vessey M. Breast cancer screening 1991: evidence and experience since the Forrest report. In: $A$ report of the Department of Health Advisory Committee. Sheffield. NHS Breast Screening Programme, 1991.

2 Forrest APM. Breast cancer screening: report to the health ministers of England, Wales, Scotland and Northern Ireland. London: HMSO, 1986.

3 van Dijk JAAM, Verbeek ALM, Hendricks JHCL, Holland R. One-view versus two-view mammography in baseline R. One-view versus two-view mammography in baseline
screening for breast screening: a review. Br f Radiol 1992;
65:971-6.

4 Bland M. An introduction to medical statistics. Oxford: Oxford University Press, 1987.

5 Department of Employment. New earnings survey: part $E$ London: HMSO, 1992.

6 Department of Transport. Values for journey time savings and accident prevention. London: Department of Transport,

7 Sculpher MJ, Buxton MJ. The private costs incurred when patients visit screening clinics: the cases of screening for breast cancer and for diabetic retinopathy. Uxbridge: Brunel University, 1993. HERG Discussion Paper No 10

8 Ashby J, Buxton MJ, Gravelle H. What costs do women meet for early detection and diagnosis of breast problems? Uxbridge: Brunel University, 1989, HERG Research Report No 6.

9 Automobile Association. Motoring costs. London: AA Technical Services, 1993. 
10 Whynes DK, Walker AR, Hardcastle JD. Cost-effective screening strategies for colorectal cancer. $\mathcal{F}$ Public Health Med 1992;14:43-9.

11 Chamberlain J, Moss SM, Kirkpatrick AE, Michell M, Johns L. National Health Service breast screening programme results for 1991-2. BMF 1993;307:353-6.

12 Brown J, Rodway A, Chamberlain J, et al. The effect of fine needle aspiration cytology on the number of diagnostic biopsies and time to diagnosis in a breast screening programme. The Breast. 1994;3:103-108.

13 Valentin J, Leitz W. Mass screening for breast cancer: benefits, risks, costs. Med Oncol Tumour Pharmacother 1988; 5:77-83.

14 Ellman R, Angeli N, Christians A, Moss J, Chamberlain J,
Maguir P. Psychiatric morbidity associated with screening for breast cancer. Br $\mathcal{F}$ Cancer 1989;60:781-4.

15 Lerman C, Trock B, Rimer BK, Boyce A, Jepson C, Engstrom PF. Psychological and behavioural implications of abnormal mammograms. Ann Intern Med 1991;114:657-61.

16 Gram IT, Lund E, Slenker SE. Quality of life following a false positive mammogram. Br f Cancer 1990;62:1018-22. 17 Bull AR, Campbell MJ. Assessment of the psychological impact of a breast screening programme. Br f Radiol 1991; 64:510-15.

16 Cockburn J, Staples M, Hurley SF, De Luise T. Psychological consequences of screening mammography. fournal of Medical Screening 1994;1:7-12. 